\title{
Dynamic Demand-Centered Process-Oriented Data Model for Inventory Management of Hemovigilance Systems
}

\author{
Mahnaz Sohrabi ${ }^{1}$, Mostafa Zandieh ${ }^{2}$, Behrouz Afshar Nadjafi ${ }^{1}$ \\ ${ }^{1}$ Faculty of Industrial and Mechanical Engineering, Qazvin Branch, Islamic Azad University, Qazvin, Iran \\ ${ }^{2}$ Department of Industrial Management and Information Technology, Management and Accounting Faculty, Shahid Beheshti University, Tehran, Iran
}

Objectives: This paper presents a reference data model for blood bank management to control blood inventories considering real-world uncertainties and constraints. It helps information systems identify blood product status for various critical decisions (such as replenishment, assignment, and issuing) instantly. Additionally, some significant optimization concepts of the inventory management literature for blood wastage and shortage reduction, such as clearance sale and substitution based on medical priorities, are applied in the model. Methods: The proposed model was constructed by object-oriented and ICAM (Integrated Computer Aided Manufacturing) definition $\phi$ (IDEF0) techniques for function modeling. Through semi-structured questionnaires and interviews, the research team elicited and classified user requirements. Then, the demand-centered sub-processes and comprehensive functions were mapped to manage the process. Results: The model captures and integrates the top-level features of the inventory system entities. It also provides insights into a developed data dictionary to understand the system's elements and attributes, where a data item fits in the structure, and what values it may contain. For designing the system's process and following-up data, the main relevant inputs are considered. Conclusions: A flexible and applicable demand-centered framework for managing a typical blood bank's inventory process was developed by focusing on user requirements. The proposed model can be applied to design and monitor inventory information and decision-support systems. The model provides real-time iterative dynamic process insights. It can also provide the data needed for logistic planning systems and the design of blood operational infrastructure.

Keywords: Blood Bank, Hospital Information System, Hospital Inventory, Process Assessment Health Care, System Analysis

Submitted: May 14, 2020

Revised: October 28, 2020

Accepted: January 19, 2021

\section{Introduction}

\section{Corresponding Author}

Mostafa Zandieh

Department of Industrial Management and Information Technology, Management and Accounting Faculty, Shahid Beheshti University, Shahid Shahriari Square, Daneshjou Boulevard, Tehran 1983963113, Iran. Tel: +98-9123588698, E-mail: m_zandieh@sbu.ac.ir (https:// orcid.org/0000-0003-1209-9514)

This is an Open Access article distributed under the terms of the Creative Commons Attribution Non-Commercial License (http://creativecommons.org/licenses/by$\mathrm{nc} / 4.0 /$ ) which permits unrestricted non-commercial use, distribution, and reproduction in any medium, provided the original work is properly cited.

(C) 2021 The Korean Society of Medical Informatics

The variation of demand, limited supply, and perishability of blood products results in a high degree of uncertainty and complexity in hemovigilance systems [1]. The effective management of blood products in this segment of the blood supply chain plays a crucial role in decreasing unnecessary costs, wastage, and shortages [2]. One of the primary concerns of blood banks, as an essential part of the blood transfusion chain, is identifying and separating the system's activities and components. Hence, user requirements should be recognized to organize the resources and functions that 
must be applied in the system $[3,4]$.

During the last decade, data follow-up has played a crucial role in successful process improvement. It has aided the delivery of more effective and responsive services [5]. Process modeling is a crucial aspect of designing information systems (ISs) [6,7]. It describes and identifies the sorts of processes/sub-processes that should be targeted in implement- ing the system and what kind of data should be followed-up [8-10]. Several studies have discussed healthcare processes considering managerial problems [11-13]. However, few of them have focused on developing blood management optimization $[4,14]$.

In this study, we conducted a process-oriented analysis of blood bank inventory management systems. The main ob-

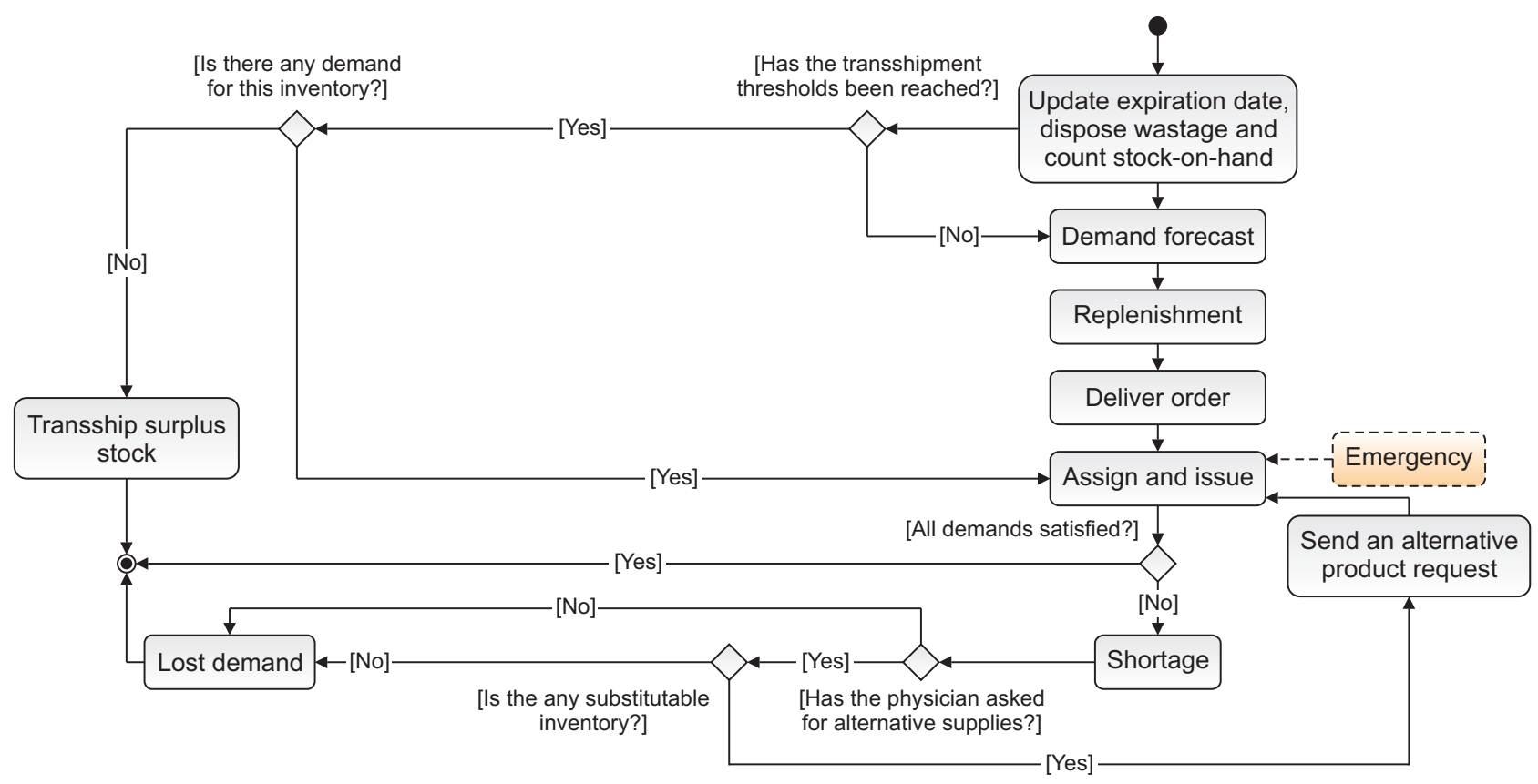

Figure 1. Activity diagram of the overall process of the hospital blood bank inventory system.

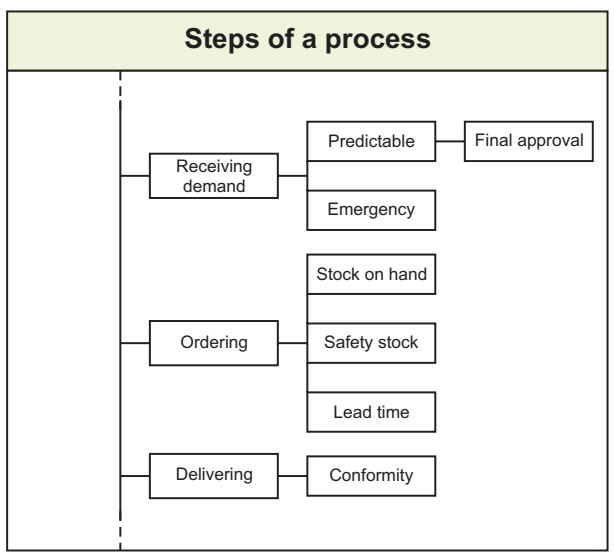

The inventory management process is demand-oriented

\begin{tabular}{|c|c|c|}
\hline \multicolumn{3}{|r|}{ Measure of parameters } \\
\hline Yes & $\begin{array}{l}\text { No } \\
\square\end{array}$ & Updating on-hand stock \\
\hline Yes & $\stackrel{\text { No }}{\square}$ & Discard expired items \\
\hline Yes & No & $\begin{array}{l}\text { Conformity between ordered } \\
\text { item and delivered one }\end{array}$ \\
\hline $\begin{array}{l}\text { Yes } \\
\square\end{array}$ & $\begin{array}{l}\text { No } \\
\square\end{array}$ & Stock-out-based substitution \\
\hline Yes & $\stackrel{\text { No }}{\square}$ & Unsatisfied demand \\
\hline
\end{tabular}
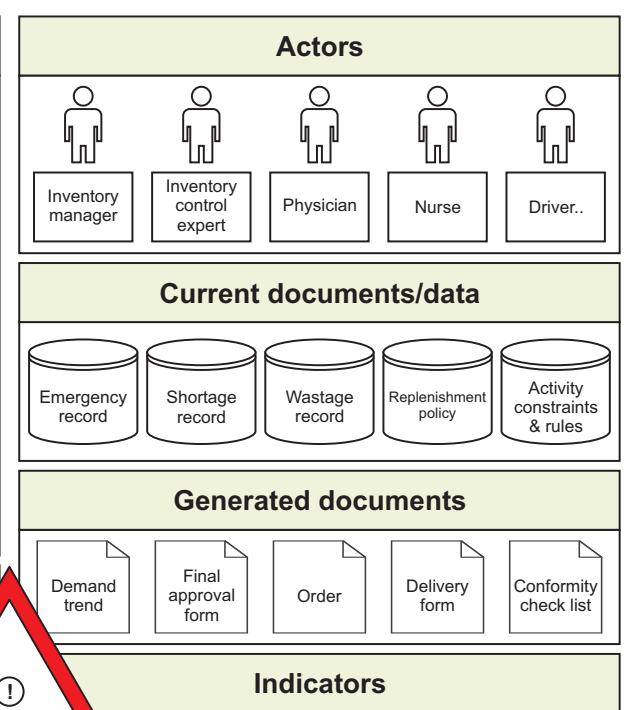

ansshipment
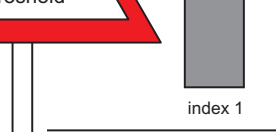

Indicators

Key: $\begin{gathered}\text { Completed } \\ \square\end{gathered} \begin{gathered}\square \\ \begin{array}{c}\text { Partially } \\ \text { completed }\end{array}\end{gathered} \begin{gathered}\text { Not } \\ \text { completed }\end{gathered}$

Figure 2. Elements of the system. 
jective was to improve the existing procedures and integrate them by proposing a reference process model as a practical infrastructure for an IS and provide a context for decision support system design. This study developed an applicable demand-centered reference model framework. A data dictionary was abstracted for designing the clinical information system module considering user requirements by process data modeling in a real case. The proposed model includes a method that shows how the structure can be composed of a repository of building blocks based on a real case.

\section{Case Description}

\section{Study Design}

This investigation was based on a case study of a tertiary referral cardiac hospital in Tehran City. The hospital is subspecialized in cardiac care and is one of the largest cardiac hospitals in Asia. The hospital's blood bank management team is responsible for policy-making, planning, and ordering the inventory of blood products required by the hospital's various departments for the central blood bank. The
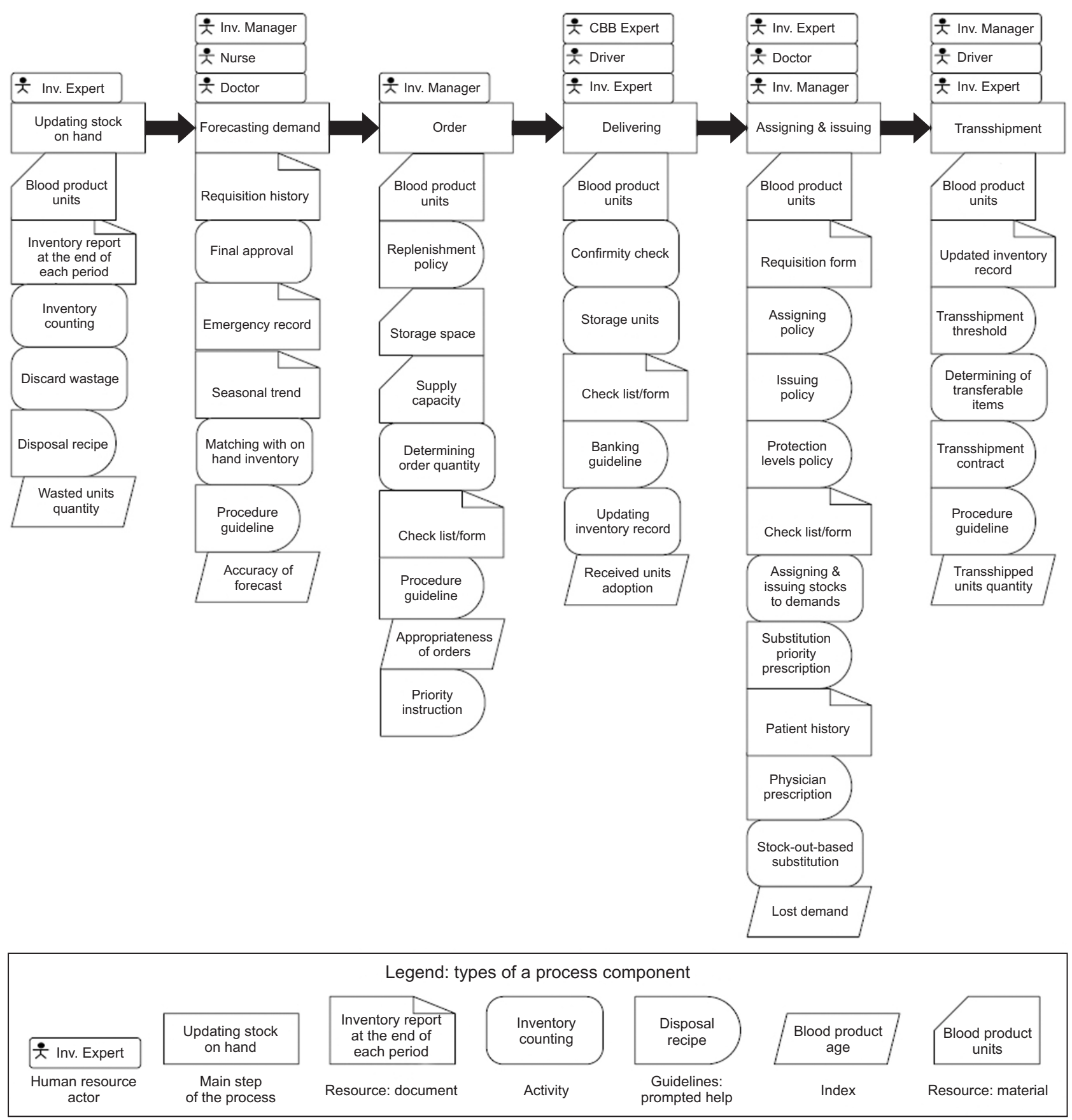

Figure 3. The main steps of the blood inventory management process at the hospital blood bank and their components. 
products under study are blood-derived products with $\mathrm{ABO} /$ $\mathrm{Rh}$ blood group types.

The inventories have finite lifetimes with age-differentiated demand. The system serves various hospital departments, where storage space is limited.

The main challenge is to hold enough stock to prevent the loss of life due to shortages with minimum expiration. Demands can be satisfied with the same or a substitutable blood type using predefined assignment and issuance policies and medical priority instructions. Shortages are not allowed and are considered as losses. In emergency conditions, demands can be satisfied through an expedited service. A clearance sale occurs for any nearly outdated units that have not been transfused at the end of each period to reduce the number of wasted units.

\section{Methods}

The methodology applied in this research is organized into the following three main steps:

- Identification, analysis, and representation of the blood bank's general inventory management process and depicting its main components. The weaknesses of the current system in meeting user requirements are identified in this step. This step is conducted through observation and interviewing of members involved in blood transfusion at the central blood bank and the hospital blood bank. In our case study, 10 participants were selected by sampling to achieve representativeness or comparability through the typical case sampling method [15];

- Describing, separating, and organizing the activities and sub-processes' elements. This step is conducted through a partnership of the hemovigilance quality-improvement working groups (consist of the selected blood bank staff, nurses, and doctors). In our case study, for this purpose, a semi-questionnaire was prepared to be answered by the participants. The obtained data is analyzed by using the ICAM (Integrated Computer Aided Manufacturing) definition $\phi$ (IDEF0) technique $[16,17]$. The structured analysis of the documents consists of the object's type, and explanation of its attributes and related methods are conducted in this step;

- Proposing an accessible object-oriented design for a typical blood bank's inventory management process considering user requirements and information collected during the previous steps. This step is conducted through objectoriented programming [18] using unified modeling language (UML) $[19,20]$.

\section{Results}

The implementation results of each step described in the previous section are reported below. A data dictionary was developed to discover process data items.

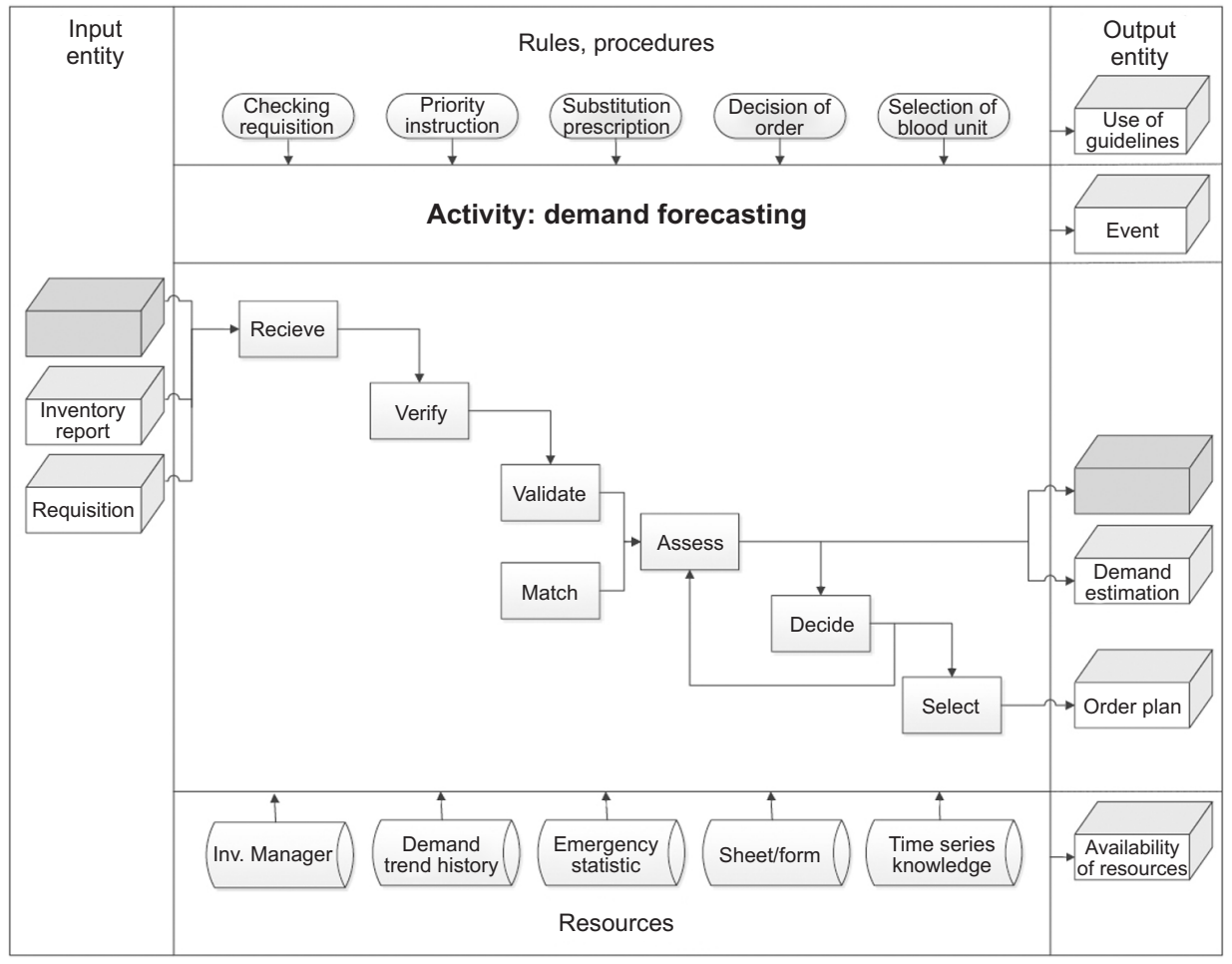

Figure 4. The Structured Analysis and Design Technique (SADT) "ICOM box" of the demand forecasting step containing components and middle entities. 


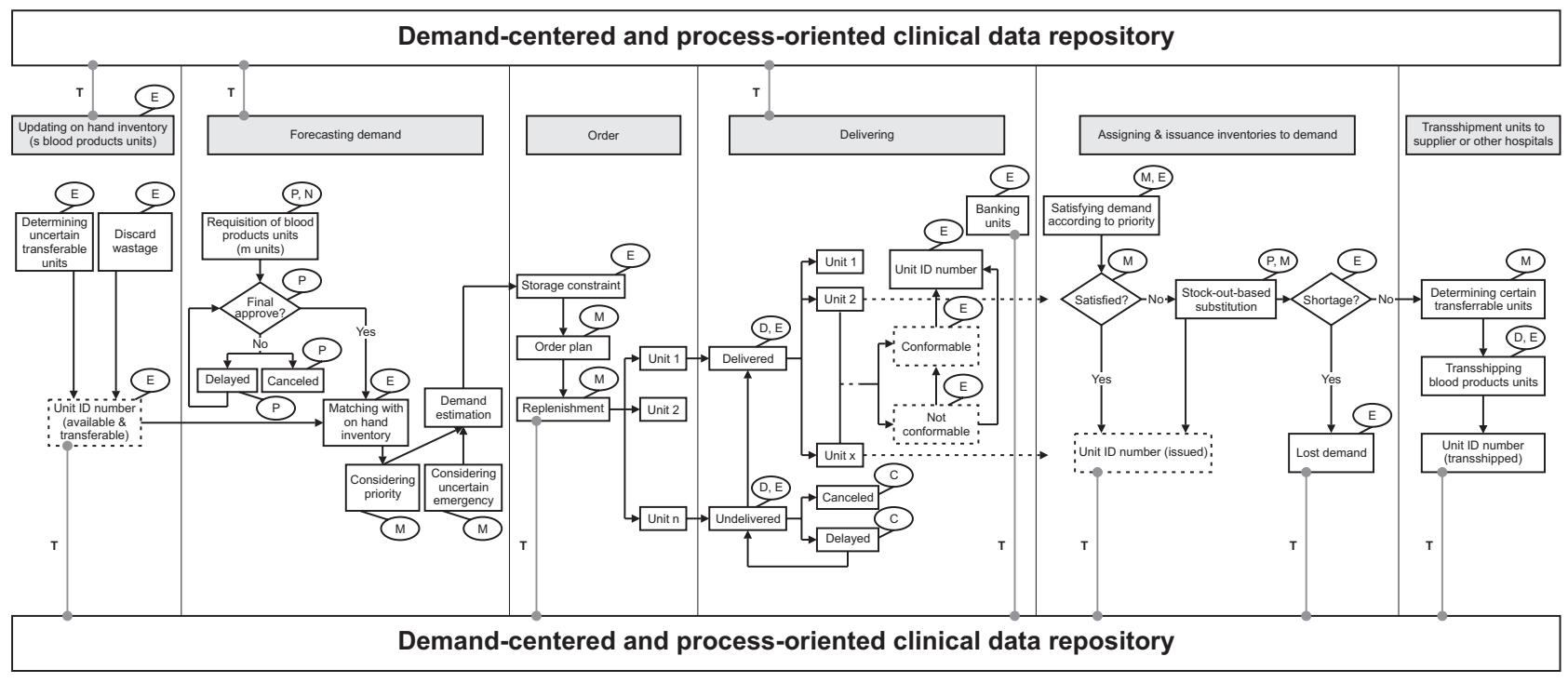

Figure 5. Data flow diagram of the hospital blood bank inventory management system and the background of tracking of the process into the demand-centered clinical data repository.

Table 1. Identification of the HBBIM-IS requirements

\begin{tabular}{ll}
\hline \multicolumn{1}{c}{ Aspect } & \multicolumn{1}{c}{ Rules } \\
\hline Users & System actors specify the user category \\
Functions & Activities or sub-processes describe user functions \\
Resource documents & Resource documents consist of data units used to outline the resource materials and their attributes \\
\hline HBBIM: blood bank inventory management process, IS: information system.
\end{tabular}

HBBIM: blood bank inventory management process, IS: information system.

Table 2. Related attributes of the prescription step of blood transfusion deduced from the analysis of the process

\begin{tabular}{|c|c|c|c|}
\hline Elements of process & Entities & Attributes & Allowed values \\
\hline \multirow[t]{12}{*}{ Demand forecasting } & Blood products & Blood type & $\mathrm{O}+, \mathrm{O}-, \mathrm{A}+, \mathrm{A}-, \ldots$ \\
\hline & & Age & $\mathrm{N}=1,2, \ldots, \mathrm{n}$ \\
\hline & & Product type & Whole blood, platelet, RBC, ... \\
\hline & & Quantity & $\mathrm{M}=1, \ldots, \mathrm{m}$ \\
\hline & & Applicant ID & Initials of the department \\
\hline & & Date of input & System date \\
\hline & & Time of input & System time \\
\hline & Demand & Status & $\begin{array}{l}\text { Planned: elective requisition-according to physician prescription, } \\
\text { emergency, periodic repetition }\end{array}$ \\
\hline & & $\begin{array}{l}\text { Reason of } \\
\text { requisition }\end{array}$ & $\begin{array}{l}\text { Organ transplants, oncology patient, traumatology, elective sur- } \\
\text { gery, and more }\end{array}$ \\
\hline & & $\begin{array}{l}\text { Substitution } \\
\text { priority }\end{array}$ & $\begin{array}{l}\text { Any suitable product, a preference for new products, no allowable } \\
\text { substitution, and more }\end{array}$ \\
\hline & & Date of input & System date \\
\hline & & Time of input & System time \\
\hline
\end{tabular}

RBC: red blood cell count. 
Table 3. Profile of the HBB inventory manager focusing on main related functions

\begin{tabular}{|c|c|c|c|}
\hline Functions & Entities & Results & Available guideline \\
\hline \multirow{2}{*}{$\begin{array}{l}\text { Demand } \\
\text { forecasting }\end{array}$} & Requisitions & Calculate current demand & Approved requisition list \\
\hline & Demand history & $\begin{array}{l}\text { Analyze historical fluctuation and trend for emergency } \\
\text { conditions }\end{array}$ & In case of emergency \\
\hline \multirow[t]{3}{*}{ Replenishment } & Order plan & Determine replenishment time and quantity & Lead time, storage capacity \\
\hline & Priority & Prioritize demands & Physician prescription \\
\hline & Finalized order list & Order new products for $\mathrm{CBB}$ & Replenishment policy \\
\hline \multirow[t]{2}{*}{$\begin{array}{l}\text { Assigning and } \\
\text { issuance }\end{array}$} & $\begin{array}{l}\text { Inventory } \\
\text { (blood product unit) }\end{array}$ & Assign and issue age-differentiated demand & $\begin{array}{l}\text { Assigning and issuance } \\
\text { policy }\end{array}$ \\
\hline & Protection level & $\begin{array}{l}\text { Determine the optimal critical level for the youngest/ } \\
\text { strategic products to limit the amount of substitution }\end{array}$ & $\begin{array}{l}\text { Critical (protection) level } \\
\text { policy }\end{array}$ \\
\hline Substitution & $\begin{array}{l}\text { History of inventory } \\
\text { (blood product unit) }\end{array}$ & Determine stock-out-based substitution & Substitution guideline \\
\hline
\end{tabular}

HBB: hospital blood bank, CBB: central blood bank.

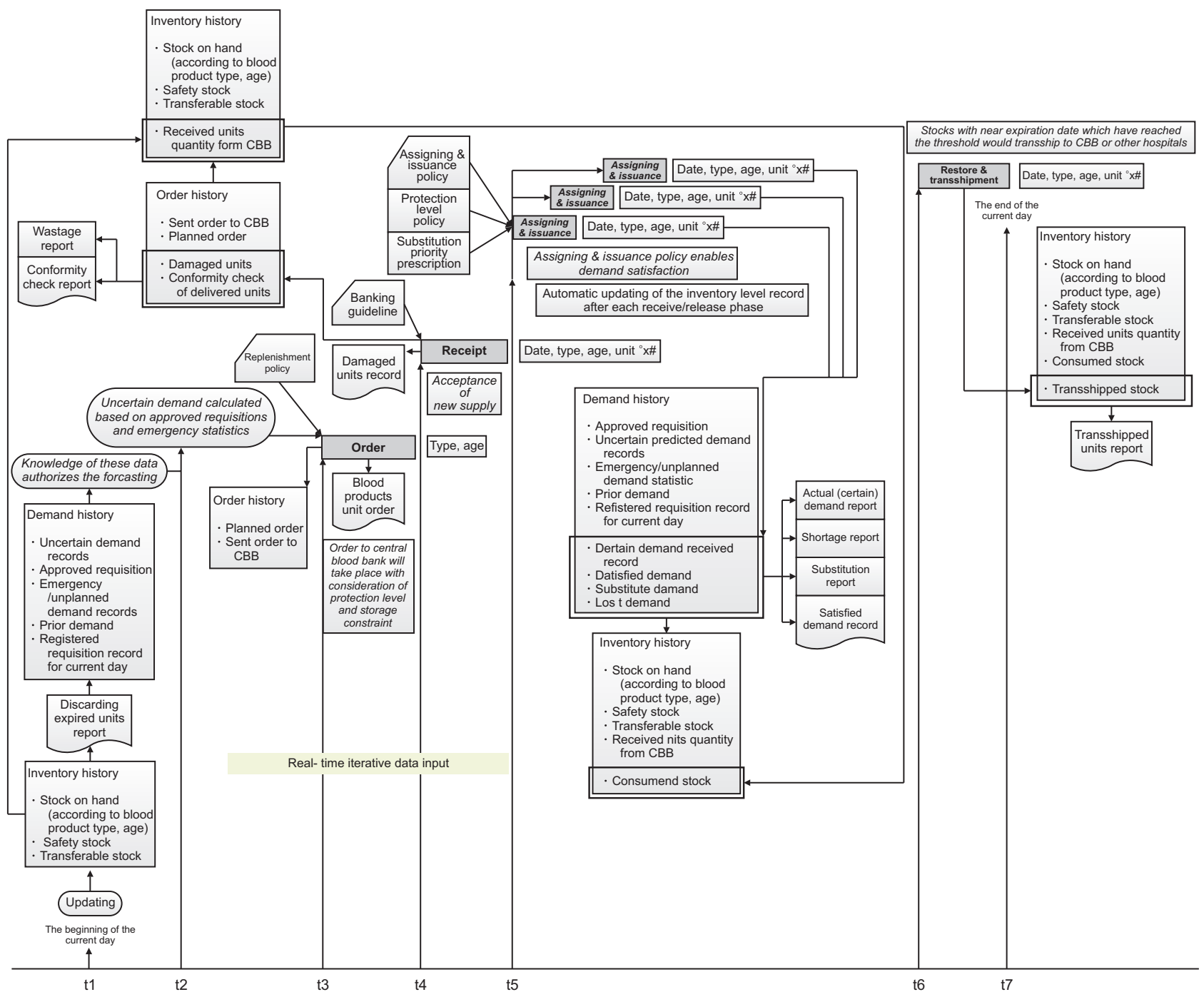

Figure 6. Integrated steps of the hospital blood bank inventory management process with time sequence shows the dynamics of the information systems. 
1) Implementation results

(1) Identification, analyzing, and representation of the general process: An overall activity diagram of the blood bank inventory management process is presented in Figure 1. Every object's behavior connected with activity responses to a series of events in the system is examined. The Structured Analysis and Design Technique (SADT) "ICOM box" extracts the details of each activity. The blood bank system has a dynamic interface with various kinds of events that change the status of the system components.

(2) Describing, separating, and organizing the activities and sub-processes' elements: As seen in Figure 2, the already defined elements consist of the following analytic quality items:

1. A set of activities at each step of inventory management considering the processing time;

2. A set of agents involved with the system at each step;

3. A set of data (such as predicted requisition, an average of planned surgeries per day, records of patients who are consistently injected) to be retrieved from the history of demands, orders, and inventory to present to the agents;

4. A set of parameters to be adjusted at each step;
5. A set of recommendations, notifications, and alarms to be considered by the actors;

6. A set of data/documents generated throughout the system, which should be exchanged, transferred, and converted among the activities;

7. A set of activity indicators related to the parameters, which should be calculated and perused to identify trends and evaluate the system's performance.

(3) Proposing an accessible object-oriented design: The core of the blood bank inventory management process includes a sequence of six sub-processes (steps), which are mapped in Figure 3. For instance, the details of a step of the process consist of an activity's components displayed by the SADT "ICOM box" scheme as shown in Figure 4. The data generated and exchanged follow the sequence, illustrated in Figure 5, of the blood bank's process steps. The actors' roles in fulfilling their responsibilities are described in detail.

The system's requirements are identified through aspects of the users, their function, and documents, as shown in Table 1. As seen in Figure 3, the appropriate indicators for various blood inventory process steps are calculated from data stored in the process steps. For instance, the characteristics of an

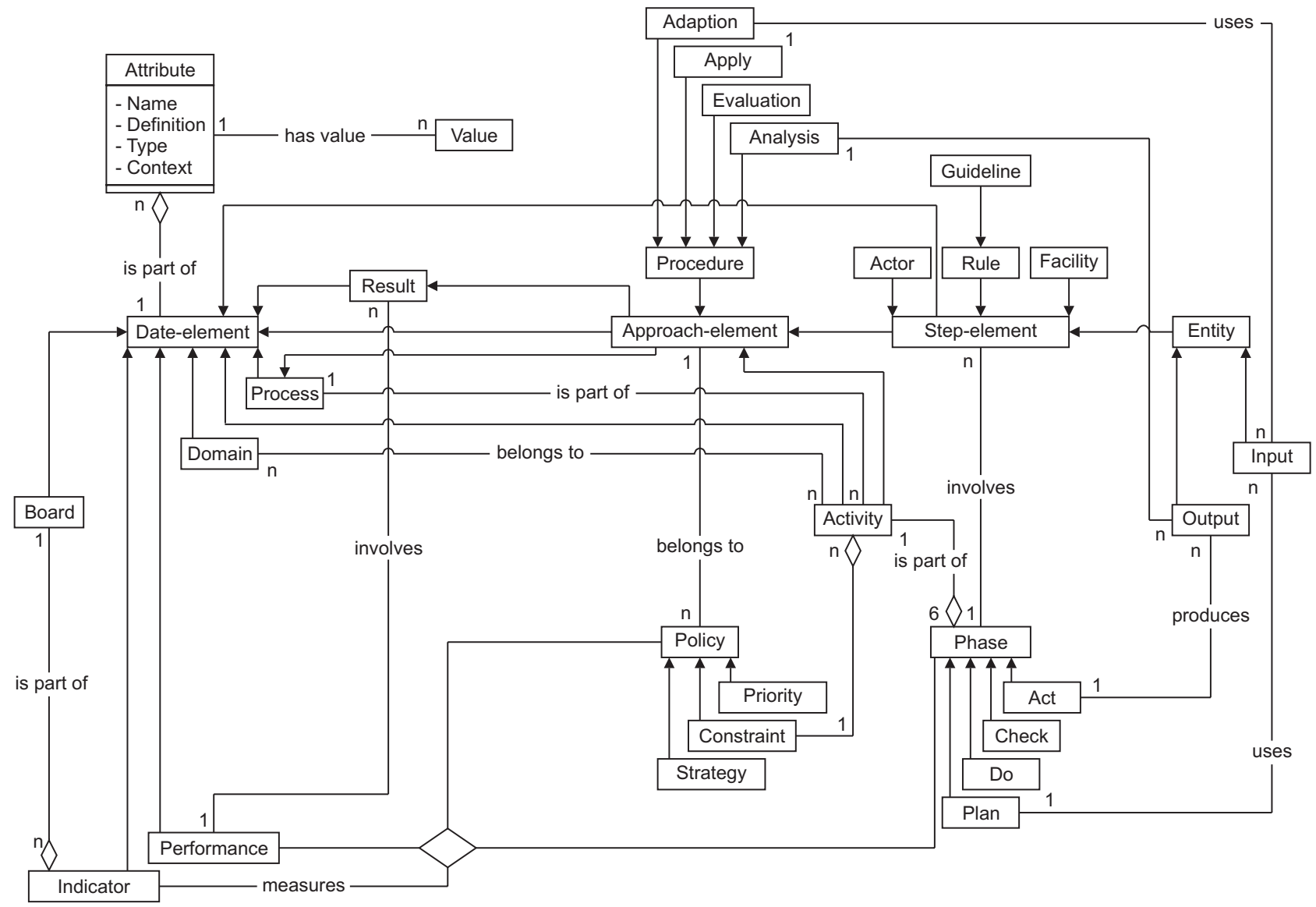

Figure 7. Object-oriented diagram of a process data model. 
element of the process (i.e., demand forecasting) are detailed in Table 2, including their entities, attributes, and allowance.

Regarding the involvement of the actors within the process, the related functions of the users are defined. For instance, the inventory manager's profile is presented in Table 3. The users' actions are integrated through the implementation of process steps. Figure 6 shows the dynamic IS actions chronologically as well as the data components that are generated, refined, modified, and exchanged within the system. A time and process-oriented analysis of the actions' purpose and the merged process steps is provided.

\section{2) Data dictionary}

A data dictionary was developed from a top-level perspective to understand where a data item fits in the structure, what values it may contain, and basically what its elements and attributes are in real-world terms. Figure 7 illustrates an abstract model of various entities and the characteristics of their relationships within the process.

(1) Step element: This element is associated with subprocesses and activities' components and is extracted from the SADT "ICOM box" scheme. It includes the interactions between the process and the inputs and outputs that tie the process' activities together.

(2) Approach element: The plan-do-check-act (PDCA) cycle and risk-based thinking push an organization to plan and make up its processes and interactions. This element ensures that the process is adequately resourced and managed, and opportunities for improvement are determined and acted on as well.

(3) Data element: The fundamental data structure in a data processing system consists of the logical definitions of the data units and the specific ranges of values discovered within the system. This element describes the step element and measures its related indicators and performance.

\section{Discussion}

Many studies have explored various aspects of techniques, process-based questions, and case studies applied to healthcare process mining. In this regard, some process-based approaches have been recently adapted for blood inventory analysis $[14,20]$. The majority of the state-of-the-art process models search for complete, so-called "start-to-end" processes. However, in highly dynamic and flexible settings, such as the one this study addresses, they fail to achieve appropriate results or appear to have limited effectiveness. This paper adds basic knowledge for efficiently improving blood bank- ing quality and bridging existing models' gaps by considering user requirements and real-time iterative dynamic processes. It is recommended to apply a compatible mathematical optimization model to the proposed model to provide optimal decisions. The presented model is also beneficial for designing the back-end of decision-support systems in practice.

\section{Conflict of Interest}

No potential conflict of interest relevant to this article was reported.

\section{ORCID}

Mahnaz Sohrabi (https://orcid.org/0000-0002-3037-6418)

Mostafa Zandieh (https://orcid.org/0000-0003-1209-9514)

Behrouz Afshar Nadjafi (https://orcid.org/0000-0002-3391-8411)

\section{References}

1. Hosseini-Motlagh SM, Samani MR, Homaei S. Blood supply chain management: robust optimization, disruption risk, and blood group compatibility (a real-life case). J Ambient Intell Humaniz Comput 2020:11(3):1085-104.

2. Haeri A, Hosseini-Motlagh SM, Ghatreh Samani MR, Rezaei M. A mixed resilient-efficient approach toward blood supply chain network design. Int Trans Oper Res 2020;27(4):1962-2001.

3. Jensen HG. IT in Blood banks, at present and tomorrow: a Nordic perspective. ISBT Sci Ser 2020;15(1):52-8.

4. Staccini P, Joubert M, Quaranta JF, Fieschi D, Fieschi M. Modelling health care processes for eliciting user requirements: a way to link a quality paradigm and clinical information system design. Int J Med Inform 2001; 64(2-3):129-42.

5. Miah SJ, Hasan N, Gammack J. Follow-up decision support tool for public healthcare: a design research perspective. Healthc Inform Res 2019;25(4):313-23.

6. Sligo J, Gauld R, Roberts V, Villa L. A literature review for large-scale health information system project planning, implementation and evaluation. Int J Med Inform 2017;97:86-97.

7. Goossen WT. Detailed clinical models: representing knowledge, data and semantics in healthcare information technology. Healthc Inform Res 2014;20(3):163-72.

8. Kwon IH. Book Review: Process mining: discovery, conformance and enhancement of business process- 
es. Healthc Inform Res 2014;20(2):157-8.

9. Pakdil F, Harwood TN, Isin FB. Implementing lean principles in the healthcare industry: a theoretical and practical overview. In: Wickramasinghe N, Bodendorf F, editors. Delivering superior health and wellness Management with IoT and analytics. Cham, Switzerland: Springer; 2020. p. 383-413.

10. dos Santos Garcia C, Meincheim A, Junior ER, Dallagassa MR, Sato DM, Carvalho DR, et al. Process mining techniques and applications: a systematic mapping study. Expert Syst Appl 2019;133:260-95.

11. Kim E, Kim S, Song M, Kim S, Yoo D, Hwang H, et al. Discovery of outpatient care process of a tertiary university hospital using process mining. Healthc Inform Res 2013;19(1):42-9.

12. Pereira Detro S, Santos EA, Panetto H, Loures ED, Lezoche M, Cabral Moro Barra C. Applying process mining and semantic reasoning for process model customisation in healthcare. Enterp Inf Syst 2020;14(7):983-1009.

13. Quinn JG, Conrad DM, Cheng CK. Process mining is an underutilized clinical research tool in transfusion medicine. Transfusion 2017;57(3):501-3.

14. Farrugia B. WASP (write a scientific paper): Sampling in qualitative research. Early Hum Dev 2019;133:69-71.
15. Baghbani M. IDEF0 Modeling Standard: a tool for process map drawing under requirements of ISO 9001: 2015: a case study. J Mod Process Manuf Prod 2019;8(4): 57-66.

16. Walker AE, Grimshaw J, Johnston M, Pitts N, Steen N, Eccles M. PRIME: Process modelling in ImpleMEntation research: selecting a theoretical basis for interventions to change clinical practice. BMC Health Serv Res 2003;3(1):22.

17. Blaschek G. Object-oriented programming: with prototypes. New York (NY): Springer Science \& Business Media; 2012.

18. Ayatollahi H, Hosseini SF, Hemmat M. Integrating genetic data into electronic health records: medical geneticists' perspectives. Healthc Inform Res 2019;25(4):28996.

19. Priestley M. Practical object-oriented design with UML. Boston (MA): McGraw-Hill; 2003.

20. Cheng C, Kumar-Misir A, Watson S, Macleod J, Sadek I. Evaluation of the real-world impact of the process mining methodology on a quality assurance process for auditing red blood cell inventory: two case studies. Can J Pathol 2017;9 Suppl:28-9. 